\title{
$\mathrm{PMV}$ 제어에 따른 사무소 건물의 실내열환경과 에너지소비량 분석
}

\section{Analysis of Indoor Thermal Environment and Energy Consumption in Office Building Controlled by PMV}

\author{
장향인*·서승직**

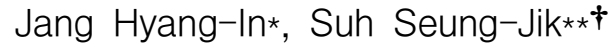

(Submit date : 2013. 4. 26., Judgment date : 2013. 5. 8., Publication decide date : 2013. 7. 23.)

\begin{abstract}
The purpose of this study is to analyse the effects of air conditioned room controlled by PMV(Predicted Mean Vote) for energy consumption and human comfort in office building. The 'EnergyPlus' was used for the evaluation of indoor thermal environment and energy consumption by the controls of room temperature and PMV. The result indicates that the PMV control could prove more profitable method for improvement of indoor thermal environment and energy conservation. Consequently, PMV control has a distinct advantage over most other control methods. An additional study is required to establish the various thermal comfort control for rooms on the basis of this work.
\end{abstract}

Key Words : 열쾌적(Thermal Comfort), 평균예상온냉감(PMV), 실제어(Room Control), 에너지소비(Energy Consumption), 에너지플러스(EnergyPlus)

\section{1. 서 론}

정부는 국제 유가 상승에 따른 경제적 부담 과 전력의 안정적 수급을 위해 냉·난방 온도 를 강력히 규제하고 있다. 이 같은 건물 실내 온도 규제는 에너지 절약 측면에서는 실효성
이 있지만 거주자 쾌적성 측면에 있어서는 매 우 단편적인 정책이다. 최근 거주자의 생활수 준 향상과 의식 변화로 인해 쾌적한 실내 환 경에 대한 요구가 증대되고 있으며, 재실자의 쾌적감 향상은 생산성 증대로 이어진다. 하지 만 일반적으로 사용되는 실내온도를 이용한
**† 서승직(교신저자) : 인하대학교 건축공학과

E-mail : energeti@inha.ac.kr, Tel : 032-873-5277

*장향인 : 인하대학교 대학원 건축공학과
**† Suh Seung-Jik(corresponding author) : Department of Architectural Engineering, Inha University.

E-mail : energeti@inha.ac.kr, Tel : 032-873-5277

*Jang Hyang-In : Department of Architectural Engineering, Graduate School, Inha University. 
공조존의 제어는 직관적이고 편의성이 높긴 하지만 거주자의 열적 쾌적성을 만족시킬 수 있는 온열 환경 변수를 모두 고려한 제어가 아니기 때문에 한계를 내포하고 있다. 반면 다 양한 온열 환경 변수들이 고려된 쾌적 지표를 활용하여 실을 제어하는 것은 다소 복잡하긴 하지만 에너지 절감과 실내 환경 개선이라는 두 가지 측면을 모두 달성할 수 있다.

이에 본 연구에서는 중앙공조방식의 사무소 를 대상으로 온도 제어와 쾌적지표 제어에 따 른 실내 온열 환경과 에너지 소비 특성을 비 교하는 것을 목적으로 하며, 이를 통해 에너지 절감과 실내 쾌적성 증대를 동시에 달성할 수 있는 제어 방법에 대한 기초 자료를 제공하고 자 한다. 본 연구는 건물 에너지 동적 해석 프 로그램인 EnergyPlus를 이용한 시뮬레이션을 통해 수행하였으며, 실온 제어 공간과 쾌적지 표 제어 공간의 실내 온도, PMV, 에너지 소비 량 등에 대해 분석하였다.

\section{2. $\mathrm{PMV}$ 제어 방법 및 선행 연구 고찰}

\subsection{PMV 지표}

인체의 생산열량과 방열량이 평형을 이루어 덥지도 춥지도 않을 때가 열쾌적 상태이다. 이 같은 열쾌적은 온도, 습도, 기류, 복사열등의 물리적 인자와, 착의량, 활동량, 성별, 나이 등 의 주관적 인자에 의해 결정된다. 열환경 평가 에 이들 전요소를 고려하는 것이 이상적이나 평가가 복잡해지고 직감성을 상실하므로, 복 수의 인자를 반영한 유효온도, 작용온도, 등가 온도, 평균예상온냉감(PMV) 등의 단일 열쾌 적 지표들이 개발되어 사용되고 있다. 이 중 PMV(Predicted Mean Vote)는 대표적인 열쾌 적 지표의 하나로 P. O. Fanger에 의해 제안 된 것으로, ISO 7730에 채택되어 사용되고 있
다. 재실자의 온열 쾌적에 영향을 미치는 6 가 진 인자(온도, 습도, 기류속도, 평균복사온도, 착의량, 활동량)을 반영하여 계산되며, -0.5 +0.5 를 쾌적 범위로 판단한다. ${ }^{1}$

\subsection{EnergyPlus를 이용한 PMV 제어 방법} 시뮬레이션 툴인 EnergyPlus는 미국 에너 지부(Department of Energy)가 BLAST와 $\mathrm{DOE}-2$ 의 장점을 결합해 만든 동적 열부하 해 석 엔진으로 ASHRAE Standard 140- 2007 표준에 따라 상용 프로그램 간의 비교를 통해 검증된 프로그램이다. 건물, 공조시스템, 열원 기기 사이의 피드백을 통해 통합된 동시계산 을 수행하며, 특히 건물(공조 존)에서의 PMV 제어로 인한 부하 변동을 공조 및 열원 기기 의 에너지 사용과 연동하여 반복 계산을 통해 수렴시켜 계산할 수 있다.

EnergyPlus에서의 PMV 제어는 사용자가 스 케줄로 입력한 기류속도, 착의량, 활동량과 이전 타임 스텝에서 계산된 습도와 평균복사온도를 입력해 지정된 PMV 설정 값을 만족시키는 실내 온도를 계산하고 이를 조절하여 수행한다. 단, 실내온도는 지정된 최대 및 최소 범위에서 변동 되며 이 값을 벗어날 경우 기본 온도 제어로 복 귀한다. 평균복사온도는 존 평균, 표면 가중 평 균, 입체각 평균 등의 계산 방법이 제공되며, 재 실자가 실의 중앙에 위치하는 것으로 가정하는 경우 존 평균 방법을 이용하여 계산할 수 있다. ${ }^{2)}$

\section{3 선행 연구 고찰}

이미 국내·외에서 쾌적지표와 관련된 많은 연구들이 수행되었으며, 특히 쾌적지표를 개

1) ISO 7730, Ergonomics of the thermal environment, 2005.

2) DOE, EnergyPlus 6.0 Engineering Reference, US Department of Energy, 2010. 
선하거나 다양한 공조 시스템과 온도 조건에 서 실내 열쾌적을 비교하는 연구들이 활발히 수행되고 있다. 또한 실의 $\mathrm{PMV}$ 제어 효과에 관련된 연구도 일부 수행되었다.

$\mathrm{PMV}$ 제어 효과를 분석한 주요 연구들을 살펴보면, 성남철 외의 연구에서는3) 난방기 공동주택의 온도 제어와 $\mathrm{PMV}$ 제어에 따른 실내 환경과 에너지 소비를 시뮬레이션을 통 해 비교하였다. 이 연구에서는 온열 쾌적감을 고려했을 때 $24^{\circ} \mathrm{C}$ 를 적정 실온으로 제시했으 며, $\mathrm{PMV}$ 제어 시 약 $6.4 \%$ 의 에너지 절감량을 보이는 것으로 분석했다. 문정현 외는4) 실험 실 측정을 통해 $\mathrm{PMV}$ 제어의 효과를 분석하 였다. 냉방 조건에서 $\mathrm{VAV}$ 시스템과 복사 냉 각 패널을 이용해 실험을 실시하였으며 에너 지 절감 효과를 확인하였다. 또한 모백현 외의 연구에서는5) $\mathrm{PMV}$ 제어 해석이 가능한 프로 그램을 개발하고, 실온 제어 시 불쾌적 구간의 발생을 확인하였으며, 평균복사온도가 $\mathrm{PMV}$ 제어에 주요한 인자인 것으로 판단하였다.

하지만 분석 기간과 시스템이 제한적인 기 존 연구들과 함께 쾌적 지표 제어가 효율적으 로 이용될 수 있는 중앙공조시스템의 건물을 대상으로 연간 성능 평가를 수행할 필요성도 확인되었다.

3) 성남철, 윤동원, 공동주택에서 쾌적지표를 활용 한 난방제어 시 온열환경 변화와 에너지소비 특 성에 관한 연구, 한국생활환경학회 논문집, 17 권 6호, pp 758-765, 2010.

4) 문정현, 임병찬, HVAC 실험실에서 공조시스템 의 PMV 제어에 의한 에너지 절약효과 연구, 한 국생활환경학회 논문집, 11권 2호, pp 111-116, 2004.

5) 모백현 외, PMV 제어공간의 온열 쾌적 및 에너 지 소비 특성에 관한 연구, 한국건축친환경설비 학회 추계학술발표대회, pp. 70-73, 2008.

\section{3. 시뮬레이션 개요}

\section{1 해석 모델 개요}

해석 모델은 $35 \mathrm{~m} \times 35 \mathrm{~m}$ 의 정방형 형태의 사 무소 기준층으로 선정하였다. 해석 모델은 1 개의 내주부, 4 개의 외주부와 공조 존 상부의 1 개의 플래넘으로 구성하였으며, 외주부의 깊이는 $5 \mathrm{~m}$ 로 설정하였다. 플래넘 상부와 공조존 바닥은 단 열(Adiabatic) 조건으로 설정하여 인접 존과의 열교환은 없는 것으로 가정하였고, 내·외부 존은 열저항이 매우 작은 비축열 재료를(Nomass)를 이용해 구획하였다. 외벽의 경우 건식 알루미늄 복합패널구조(알루미늄패널+공기층+단열재+석 고보드)로, 창호의 경우 알루미늄프레임 $+24 \mathrm{~mm}$ $\mathrm{Low}^{-} \mathrm{e}$ 복층유리로 가정하였다. 해석 모델의 개 요 및 물성은 다음 Table. 1과 같다.

Table 1 Specifications of Building

\begin{tabular}{lc}
\hline Floor Plan & $1,225.0 \mathrm{~m}^{2}$ \\
\hline Floor Area & $40 \%$ \\
\hline WWR & $3.6 \mathrm{~m}$ \\
\hline Floor Height & $2.7 \mathrm{~m}$ \\
\hline Ceiling Height & Office \\
\hline Use of Building & 0.384 \\
\hline U-value of Wall & 2.371 \\
\hline U-value of Window & 0.569 \\
\hline SHGC of Window
\end{tabular}

\section{2 시뮬레이션 입력 조건}

시뮬레이션 분석을 위한 $\mathrm{HVAC}$ 시스템의 구성은 다음 Fig. 1과 같다. 공조 시스템은 중 앙공조방식에서 사용빈도가 높은 $\mathrm{VAV}+\mathrm{FCU}$ (외주부) 방식으로 구현했으며, 열원 기기는 가스보일러와 수냉식 전기칠러를 이용하여 구 성하였다. $\mathrm{VAV}$ 터미널 박스의 풍량 제어는 
냉방뿐만 난방 시에도 최대 풍량의 설정이 가 능한 Dual Maximum 제어 로직을 이용했으 며, 건구 온도에 의한 외기 냉방을 도입하였 다. 냉각코일은 12 월 2 월까지, 주난방코일은 6 월 8월까지 가동을 멈추도록 설정했다.

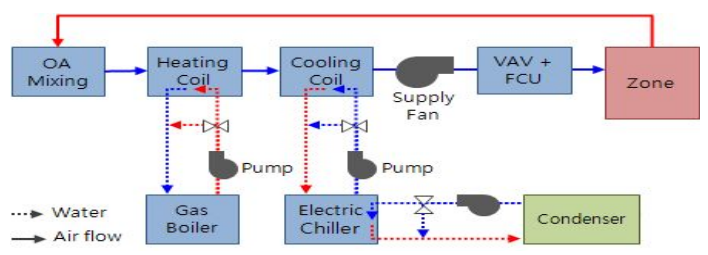

Fig. 1 HVAC System Components

재실 및 발열 스케줄은 ASHRAE Standard 90. 1(1989)에 준해 Fig. 2와 같이 입력했다.6) 내부 열취득은 ASHRAE Handbook Fundamentals (2009)의 기준을, 재실밀도 및 외기도입량은 ASHRAE Standard 62.1 (2007)의 기준을 사용 하였다.7)8) 분석을 위한 기상 파일은 EnergyPlus 에서 제공하는 인천 지역 데이터를 사용했으 며, 시뮬레이션 입력 조건은 다음 Table 2에 HVAC 시스템은 Table 3 에 나타냈다.

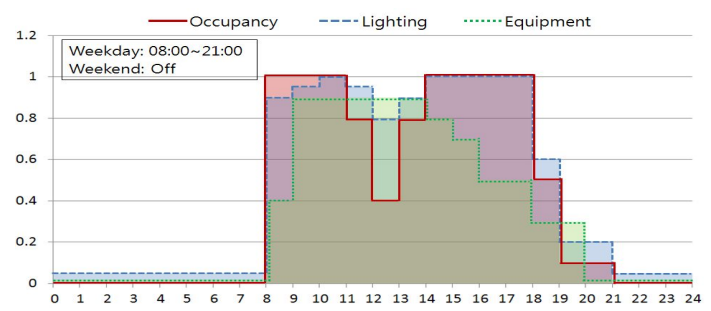

Fig. 2 Occupancy, Light and Equipment Schedules

6) ASHRAE, ASHRAE Standard 90. 1, Energy Standard for Buildings Except Low-Rise Residential Buildings, ASHRAE. Inc, 1989.

7) ASHRAE, ASHRAE Handbook Fundamentals, ASHRAE. Inc, 2009.

8) ASHRAE, ANSI/ASHRAE Standard 62.1 Ventilation for Acceptable Indoor Air Quality, ASHRAE. Inc, 2007.
Table 2 Simulation Conditions

\begin{tabular}{ccc}
\hline Item & \multicolumn{2}{c}{ Condition } \\
\hline $\begin{array}{c}\text { Operation } \\
\text { Time }\end{array}$ & $\begin{array}{c}\text { Weekday : 08:00 21:00 } \\
\text { Weekend : Off }\end{array}$ \\
\hline Metabolic & $117 \mathrm{~W} /$ person & $\begin{array}{c}\text { Office Work } \\
\text { (Typing) }\end{array}$ \\
\hline Light & $12 \mathrm{~W} / \mathrm{m} 2$ & $\begin{array}{c}\text { Office } \\
\text { enclosed }\end{array}$ \\
\hline Equipment & $10.8 \mathrm{~W} / \mathrm{m} 2$ & $\begin{array}{c}\text { Office } \\
\text { Medium }\end{array}$ \\
\hline $\begin{array}{c}\text { Occupant } \\
\text { Density }\end{array}$ & 0.11 person/m2 & Office Space \\
\hline $\begin{array}{c}\text { Min. Outdoor } \\
\text { Air Rate }\end{array}$ & $28.88 \mathrm{CMH} /$ person & Office Space \\
\hline Infiltration & \multicolumn{2}{c}{0.2 ACH } \\
\hline Weather Data & Incheon, Korea (.epw) \\
\hline
\end{tabular}

실을 제어하는 쾌적 지표는 $\mathrm{PMV}$ 로 설정 하였으며, PMV 제어를 위한 기류속도, 착의 량, 활동량에 대한 입력은 ISO 및 ASHRAE 의 각종 기준을 참고하여 설정했다. ${ }^{17)}$ 착의 량 $(\mathrm{clo})$ 의 경우 스케줄을 통해 냉방기, 난방 기, 중간기를 구분해 입력하였으며, 활동량 (met)은 사무실의 중간 강도 업무로 가정해 1.1 met으로 설정하였다. 실내의 기류 속도는 $\mathrm{VAV}$ 시스템의 경우 디퓨저 주변은 풍량에 의한 영향이 있으나 대부분의 거주역에서는 영향이 거의 없으므로 기존 연구를 참조해 $0.1 \mathrm{~m} / \mathrm{s}$ 로 입력하였다.9) $\mathrm{PMV}$ 제어 시 실내 온도의 범위는 $18^{\circ} \mathrm{C} \sim 30^{\circ} \mathrm{C}$ 로 지정하였다. 평 균복사온도는 특정 표면의 가중이 없이 계산 하는 존 평균(Zone Average) 방식으로 설정 하였다. 다음 Table 4는 PMV 제어를 위한 입력값들을 나타낸다.

9) 유기형 외. 바닥공조시스템과 천장공조시스템의 실내환경 비교 평가, 대한건축학회 논문집(계획 계), 20권 5호, pp 185-192, 2004. 
Table 3 Plant \& AHU

\begin{tabular}{|c|c|}
\hline Item & Condition \\
\hline Cooling Plant & $\begin{array}{c}\text { Elec. Chiller, Water Cooled, } 150 \mathrm{~kW} \\
\text { CoP }: 3.2\end{array}$ \\
\hline Heating Plant & $\begin{array}{c}\text { Gas Boiler, } 250 \mathrm{~kW} \\
\text { Efficiency }: 0.80\end{array}$ \\
\hline $\mathrm{AHU}$ & $\begin{array}{c}\text { VAV / FCU(Perimeter) } \\
\text { Max Flow Rate }: 6.0 \mathrm{~m}^{3} / \mathrm{s}\end{array}$ \\
\hline Supply Fan & $\begin{array}{c}\text { Supply Fan : } 2.5 \mathrm{~kW}, 300 \mathrm{~Pa} \\
\text { Fan Efficiency : } 0.7\end{array}$ \\
\hline $\begin{array}{l}\text { Outdoor Air } \\
\text { System }\end{array}$ & Economizer(Drybulb Temp.) \\
\hline
\end{tabular}

Table 4 Input Parameters of PMV Control

\begin{tabular}{ccc}
\hline Parameters & Value & Remark \\
\hline Air Velocity & $0.1 \mathrm{~m} / \mathrm{s}$ & \\
\hline $\begin{array}{c}\text { Clothing } \\
\text { Value }\end{array}$ & $\begin{array}{c}\text { Dec. } \sim \text { Feb. : } 1.0 \\
\text { June } \sim \text { Aug. : } 0.5 \\
\text { Others : } 0.75\end{array}$ & Scheduled \\
\hline $\begin{array}{c}\text { Metabolic } \\
\text { Rate }\end{array}$ & $\begin{array}{c}\text { 1.1met } \\
\text { (117W/Person) }\end{array}$ & $\begin{array}{c}\text { Office Work } \\
\text { (Typing) }\end{array}$ \\
\hline
\end{tabular}

\section{3 분석 Case 구성}

시뮬레이션 Case는 다음 Table 5와 같다. Case 1은 에너지절약설계기준에 의해 실내 온도를 설정한 경우이며,10) Case 2는 예비 시 뮬레이션 분석을 통해 재실자 열쾌적 빈도가 $\mathrm{PMV}$ 제어와 비슷할 수 있도록 설정 온도 범 위를 조정한 것이다. 온도 제어 유형은 오차범 위를 가진 이중 설정값(Dual Setpoint with Deadband)으로 냉난방에 동시 대응하도록 설 정하였다. Case 3 은 공조 존의 PMV를 쾌적 범위인 \pm 0.5 이내로 제어한 경우이다.

10) 국토해양부 고시 제 2013-149, 건축물의 에너 지절약 설계기준, 2013.
Table 5 Simulation Cases

\begin{tabular}{ccc}
\hline Case & $\begin{array}{c}\text { Control } \\
\text { Variable }\end{array}$ & Set Point \\
\hline Case 1 & Temperature & $\begin{array}{l}\text { Heating : } 20.0^{\circ} \mathrm{C} \\
\text { Cooling : } 26.0^{\circ} \mathrm{C}\end{array}$ \\
\hline Case 2 & Temperature & $\begin{array}{l}\text { Heating : } 22.5^{\circ} \mathrm{C} \\
\text { Cooling : } 24.0^{\circ} \mathrm{C}\end{array}$ \\
\hline Case 3 & PMV & $\begin{array}{l}\text { Heating : PMV }>-0.5 \\
\text { Cooling : PMV }<+0.5\end{array}$ \\
\hline
\end{tabular}

\section{4. 시뮬레이션 결과 분석 및 고찰}

\section{1 제어 방법에 따른 실내온도 변화}

Table 6은 냉 - 난방기 및 연간의 남측 외주 부와 내주부의 최저온도, 최고온도, 평균온도, 온도표준편차를 나타낸 것이다. 냉방기는 6 8월을, 난방기는 12 2월을 분석했으며, 실내 열환경을 대표할 수 있는 남측 외주부와 내주 부를 비교하였다. 난방기에도 특히 내부존의 경우, 난방 부하보다 냉방 부하가 많이 발생하 여 평균 온도가 냉방 설정 온도에 가깝게 나 타났으며, 온도 제어 Case에서 설정 온도 범 위를 벗어나는 경우는 주로 공조기가 재가동 되는 월요일 아침에 발생하였으나, Night Setback Control 사용으로 인해 그 비율이 $1 \%$ 이내로 매우 낮게 나타났다.

Fig. 3은 제어 방법에 따른 각 Case에서 연 중 공조 시간의 실내 평균 온도 분포를 정리 한 것이다. PMV 제어를 한 Case 3의 경우 온 도 설정 범위가 넓은 Case 1보다는 표준편차 가 작지만, 온도 설정 범위가 좁고 평균 온도 가 비슷한 Case 2보다는 표준편차가 크게 나 타났다. 이는 PMV 제어가 다른 온열 쾌적 인 자를 반영해 실의 건구 온도를 폭 넓게 조정 하기 때문으로 판단된다. 
Table 6 Temperature Distribution of Each Zone

\begin{tabular}{|c|c|c|c|c|c|c|c|}
\hline \multirow{2}{*}{\multicolumn{2}{|c|}{$\begin{array}{r}\text { Zone } \\
\text { Case } \\
\text { Season }\end{array}$}} & \multicolumn{3}{|c|}{ South Perimeter } & \multicolumn{3}{|c|}{ InteriorZone } \\
\hline & & 1 & 2 & 3 & 1 & 2 & 3 \\
\hline \multirow{4}{*}{ Winter } & Min. & 20.0 & 22.5 & 18.4 & 20.0 & 22.5 & 21.1 \\
\hline & Max & 26.0 & 25.4 & 24.2 & 26.0 & 24.4 & 25.4 \\
\hline & Avg. & 22.3 & 23.0 & 21.7 & 24.0 & 23.7 & 24.0 \\
\hline & S.D. & 2.19 & 0.66 & 1.21 & 1.46 & 0.51 & 0.91 \\
\hline \multirow{4}{*}{ Summer } & Min. & 22.6 & 22.5 & 20.8 & 25.6 & 23.3 & 23.9 \\
\hline & Max & 26.2 & 24.0 & 25.2 & 27.6 & 26.1 & 26.5 \\
\hline & Avg. & 25.5 & 23.6 & 23.3 & 26.1 & 24.0 & 25.8 \\
\hline & S.D. & 0.70 & 0.56 & 0.98 & 0.26 & 0.23 & 0.50 \\
\hline \multirow{4}{*}{ Annual } & Min. & 20.0 & 22.5 & 18.4 & 20.0 & 22.5 & 21.1 \\
\hline & Max & 26.2 & 25.4 & 25.2 & 27.6 & 26.1 & 26.5 \\
\hline & Avg. & 24.3 & 23.3 & 22.5 & 25.5 & 23.9 & 24.9 \\
\hline & S.D. & 1.64 & 0.67 & 1.26 & 1.05 & 0.38 & 0.90 \\
\hline
\end{tabular}

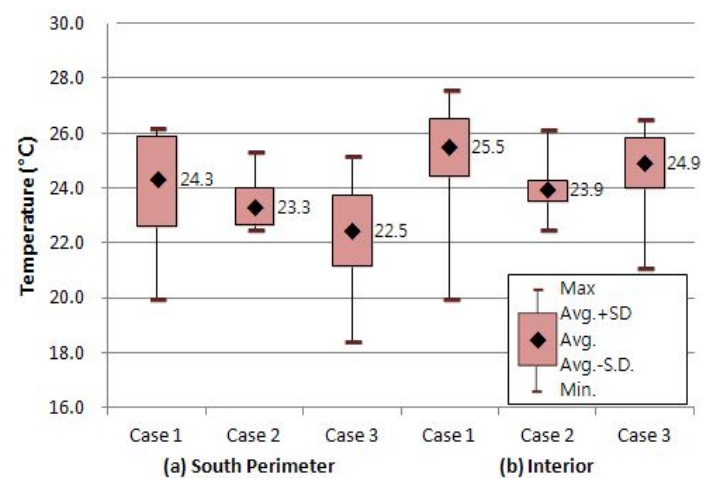

Fig. 3 Annual Variation of Zone Air Temperature

\section{2 제어 방법에 따른 $\mathrm{PMV}$ 변화}

Table 7은 냉 - 난방기 및 연간의 최저, 최 고 및 평균 $\mathrm{PMV}$ 와 표준편차를 정리한 것이 다. Fig. 4는 각 Case에서 연중 PMV 분포를 나타낸 것이다. Case 3 의 경우 Case 1 , Case 2 에 비해 $\mathrm{PMV}$ 의 분포폭이 작고, 평균값의 경 우도 더 쾌적한 범위인 0에 가까운 값을 나타 냈다. 단, 내주부의 경우 Case 2에 비해 Case
3 의 평균 $\mathrm{PMV}$ 값이 높은 것은 내부 존의 경 우 일사에 의한 복사 온도의 변화가 적고, $\mathrm{PMV}$ 제어가 설정값인 0.5 을 만족하면 온도 조정을 멈추기 때문으로 판단된다.

Table 7 PMV Distribution of Each Zone

\begin{tabular}{|c|c|c|c|c|c|c|c|}
\hline \multirow{2}{*}{\multicolumn{2}{|c|}{$\begin{array}{r}\text { Zone } \\
\text { Case }\end{array}$}} & \multirow{2}{*}{$\begin{array}{c}\text { South } \\
1\end{array}$} & \multicolumn{2}{|c|}{ Perimeter } & \multicolumn{3}{|c|}{ InteriorZone } \\
\hline & & & 2 & 3 & 1 & 2 & 3 \\
\hline \multirow{4}{*}{ Winter } & Min. & -1.03 & -0.62 & -0.85 & -0.86 & -0.43 & -0.56 \\
\hline & Max & 1.45 & 1.12 & 0.79 & 0.95 & 0.56 & 0.52 \\
\hline & Avg. & -0.04 & 0.11 & -0.13 & 0.24 & 0.22 & 0.25 \\
\hline & S.D. & 0.61 & 0.41 & 0.37 & 0.37 & 0.19 & 0.21 \\
\hline \multirow{4}{*}{ Summer } & Min. & -0.51 & -0.67 & -0.88 & 0.25 & -0.33 & -0.31 \\
\hline & $\operatorname{Max}$ & 1.16 & 0.58 & 0.60 & 1.57 & 0.99 & 1.06 \\
\hline & Avg. & 0.55 & -0.05 & -0.10 & 0.59 & -0.05 & 0.41 \\
\hline & S.D. & 0.39 & 0.32 & 0.29 & 0.19 & 0.17 & 0.17 \\
\hline \multirow{4}{*}{ Annual } & Min. & -1.24 & -0.76 & -0.88 & -0.86 & -0.50 & -0.58 \\
\hline & $\operatorname{Max}$ & 1.84 & 1.27 & 0.79 & 1.57 & 0.99 & 1.06 \\
\hline & Avg. & 0.36 & 0.09 & -0.09 & 0.55 & 0.14 & 0.36 \\
\hline & S.D. & 0.58 & 0.40 & 0.36 & 0.31 & 0.21 & 0.20 \\
\hline
\end{tabular}

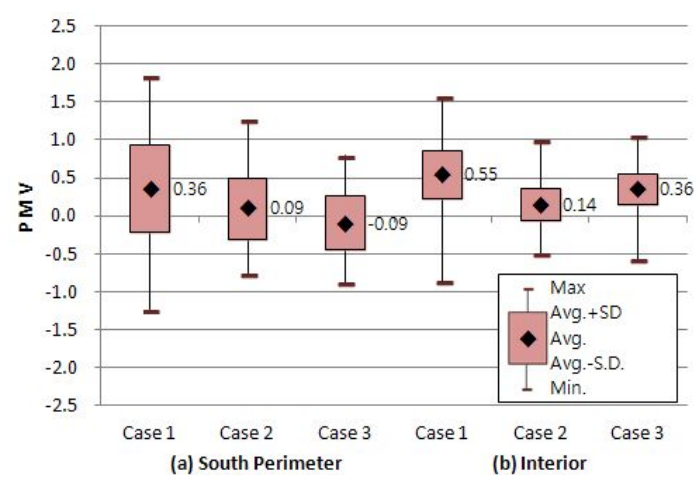

Fig. 4 Annual Variation of PMV

Table 8은 총 공조 시간 중 $\mathrm{PMV}$ 지표가 쾌적 범위인 \pm 0.5 이내인 시간을 나타낸 것이 다. 실내온도를 $20.0^{\circ} \mathrm{C} \sim 26.0^{\circ} \mathrm{C}$ 로 제어한 Case 1 의 경우 외주부는 $43.1 \%$, 내주부는 $35.7 \%$ 만 
이 쾌적 구간에 분포하였다. $\mathrm{PMV}$ 쾌적 범 위 빈도가 높아지도록 실내 온도를 $22.5^{\circ} \mathrm{C}$ $\sim 24.0^{\circ} \mathrm{C}$ 로 조정한 Case 2 의 경 우는 외주부 는 $83.6 \%$, 내주부는 $97.4 \%$ 가 $\mathrm{PMV} \pm 0.5$ 이 내에 분포하였다. PMV 제어 시에는 전체 공조 시간 중 외주부는 $85.8 \%$, 내주부는 $98.3 \%$ 가 $\mathrm{PMV} \pm 0.5$ 이내로 분석되어 공조 존이 쾌적 범위에서 적절히 제어되는 것으 로 나타났다.

Table 8 Comfortable Time Ratio

\begin{tabular}{|c|c|c|c|c|}
\hline & Case & Total & $\begin{array}{l}\text { Comfort } \\
\text { Time }\end{array}$ & Ratio \\
\hline \multirow{3}{*}{$\begin{array}{c}\text { South } \\
\text { Perimeter } \\
\text { Zone }\end{array}$} & 1 & \multirow{3}{*}{3,380} & 1,457 & $43.1 \%$ \\
\hline & 2 & & 2,827 & $83.6 \%$ \\
\hline & 3 & & 2,899 & $85.8 \%$ \\
\hline \multirow{3}{*}{$\begin{array}{l}\text { Interior } \\
\text { Zone }\end{array}$} & 1 & \multirow{3}{*}{3,380} & 1,205 & $35.7 \%$ \\
\hline & 2 & & 3,293 & $97.4 \%$ \\
\hline & 3 & & 3,324 & $98.3 \%$ \\
\hline
\end{tabular}

\section{3 제어 방법에 따른 에너지소비량 변화}

Table 9는 각 Case의 월별로 냉·난방에 사 용되는 에너지 사용량을 비교한 것이다. Case 3 의 연간 냉·난방 에너지 사용량은 Case 1 에 비해서는 $14.3 \%$ 높게 나타났으나, PMV 쾌적 구간 비율이 비슷한 Case 2에 비해서는 $6.1 \%$ 낮게 나타났다. 이는 PMV 제어가 온도 제어 보다 에너지 사용 측면에서 유리한 동시에 실 의 쾌적 비율도 높게 나타남을 보여준다. 다음 Fig. 5는 연간 냉방열원, 난방열원, 기타(팬, 펌프 등) 장비의 연간 에너지 사용량을 나타 낸 것이다. 최종 이용처별 에너지 사용량 역시 총 에너지 사용량과 유사하게 Case 1>Case $3>$ Case 2의 순서로 나타났다.
Table 9 Total Energy Consumption

\begin{tabular}{cccc}
\hline Month & Case 1 & Case 2 & Case 3 \\
\hline January & 16.86 & 19.36 & 18.24 \\
\hline February & 13.13 & 14.58 & 13.85 \\
\hline March & 5.79 & 7.05 & 6.74 \\
\hline April & 3.97 & 5.10 & 4.66 \\
\hline May & 9.16 & 11.89 & 11.41 \\
\hline June & 14.99 & 19.50 & 17.82 \\
\hline July & 21.81 & 27.14 & 25.16 \\
\hline August & 25.09 & 30.94 & 28.70 \\
\hline September & 14.16 & 18.59 & 18.26 \\
\hline October & 8.08 & 11.41 & 10.83 \\
\hline November & 5.84 & 7.87 & 7.31 \\
\hline December & 13.31 & 15.15 & 14.68 \\
\hline Sum & 152.19 & 188.56 & 177.68 \\
\hline & & &
\end{tabular}

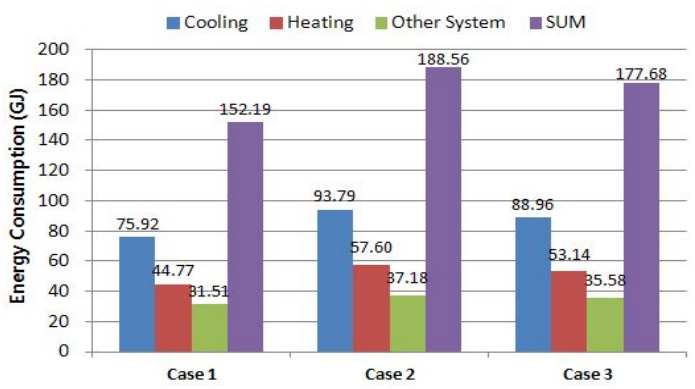

Fig. 5 Energy Consumption According to Devices

\section{5. 결 론}

본 연구는 업무 시설을 대상으로 공조 존 의 제어 방법에 따른 실내 온열 환경과 에 너지 소비량을 비교 분석한 것으로, 그 주 요 결과는 다음과 같다.

(1) 공조 존을 PMV 지표를 이용해 제어하는 경우에는 다른 온열 쾌적 인자가 반영되 어 실온 제어에 비해 실 온도의 변화 폭이 크게 나타났다. 
(2) 실내 온도를 에너지절약설계기준에 따라 난방 $20^{\circ} \mathrm{C}$, 냉방 $26^{\circ} \mathrm{C}$ 로 설정한 경우, 에너 지 소비량은 적으나 $\mathrm{PMV}$ 가 쾌적 범위인 \pm 0.5 이내인 비율은 내외주부 평균 약 $1 / 3$ 에 불과한 것으로 나타났다. 단순 온도 제 어만으로는 실의 온열 쾌적성 확보에 효 율적이지 못한 것으로 판단된다.

(3) PMV 지표를 이용해 실을 제어하는 경우 에는 온도 제어에 비해 쾌적 구간 분포 비 율이 높게 나타났다. 또한 PMV 제어 시 에는 온도 제어에 비해 실의 PMV 변화 폭이 좁고, 평균값도 완전 쾌적 값인 0에 가깝게 나타났다.

(4) PMV 제어(Case 3)의 경우 비슷한 쾌적성 을 가진 실온 제어(Case 2)에 비해 에너지 사용량이 약 $6.1 \%$ 낮게 나타나 에너지 소 비 측면에서도 유리한 것으로 분석되었다.

이상의 연구를 통해 쾌적지표(PMV)를 이 용한 공조존 제어의 효과와 활용 가능성을 확 인하였다. 이후 다양한 건물용도, 공조시스템, 재실스케줄에서의 비교와 계산된 PMV와 실 제 재실자 열쾌적을 비교하는 후속 연구를 수 행해 쾌적 지표를 이용한 공조 존 제어에 관 한 기초 자료를 구축할 예정이다.

\section{후 기}

본 연구는 인하대학교의 연구비 지원으로 수행되었음.

\section{참 고 문 헌}

1. ISO 7730, Ergonomics of the thermal environment, 2005.

2. DOE, EnergyPlus 6.0 Engineering Reference,
US Department of Energy, 2010.

3. Seong, N. C. and Yoon, D. W., Study on Thermal Environment and Heating Energy Consumption Using Thermal Comfort Index in Residential Building, Korean Journal of KSLES, Vol. 17, No. 6, pp 758-765, 2010.

4. Mun, J. H. and Ihm, P. C., Energy Savings of HVAC Systems by PMV Controls in a Full-Scale HVAC Laboratory, Korean Journal of KSLES, Vol. 11, No. 2, pp. 111-116, 2004.

5. Mo, P. H. et al, Study on Thermal Comfort and Energy Consumption Characteristic in PMV Contrlled Space, Proceeding of KIAEBS autumn conference, pp. 70-73. 2008.

6. ASHRAE, ASHRAE Standard 90. 1, Energy Standard for Buildings Except Low-Rise Residential Buildings, 1989.

7. ASHRAE, ASHRAE Handbook Fundamentals, 2009.

8. ASHRAE, ANSI/ASHRAE Standard 62.1 Ventilation for Acceptable Indoor Air Quality, 2007.

9. Yu, K. H. et al, Comparative Evaluation of Indoor Environment of Office Buildings with An Underfloor Air Distribution System and A Ceiling Based Air Conditioning System. Korean Journal of AIK, Vol. 20, No. 5, pp 185-192, 2004.

10. Ministry of Land, Transport and Maritime Affairs, Notice No. 2013-149, Building Energy Conservation Design Standards, 2013. 